\title{
Heidegger y la indicación formal: hacia una articulación categorial de la vida humana*
}

\author{
JESÚS ADRIÁN ESCUDERO \\ Facultad de Letras \\ Universidad Autónoma de Barcelona \\ jesus.adrian@uab.es
}

\begin{abstract}
Resumen: Este artículo aborda el complejo problema heideggeriano de cómo acceder adecuada y correctamente al ámbito de manifestación inmediata de la vida humana. Partiendo del concepto de hermenéutica de la facticidad, se analiza la propuesta heideggeriana de articulación categorial de la existencia humana, la cual recurre al instrumental analítico de los indicadores formales, esto es, a los conceptos básicos que sirven para explicitar reflexivamente la comprensión que la vida, el ser-ahí, tiene de sí misma. En este contexto, se intenta concretar el significado y la función de esos indicadores en la mencionada explicitación categorial de la vida: por un lado, se rastrean sus antecedentes en el caso de la comunicación indirecta de Kierkegaard y de las expresiones ocasionales de Husserl; y, por otro, se pretende mostrar hasta qué punto la posibilidad de esa explicitación se alimenta del concepto husserliano de intuición categorial.
\end{abstract}

Palabras clave: situación hermenéutica, desmontaje, vida fáctica, indicadores formales, intuición categorial

\begin{abstract}
This article tackles the complex Heideggerian problem of how can we have an appropriate access to the immediate manifestation field of human life. Taking the concept of 'hermeneutics of facticity' as the point of departure, I analyze Heidegger's proposal of a categorial articulation of human existence, in which the analytic instrumental of formal indicators are used, that is, the basic concepts serving to make explicit, in a reflective manner, the comprehension that life, Dasein, has of itself. In this context I try to explain the meaning and function of these indicators in the categorial explication of life: on the one hand, I trace its antecedents to the case of indirect communication by Kierkegaard, and the occasional expressions by Husserl; on the other, I show whether it is possible for such an explication to be nourished by the Husserlian concept of categorial intuition.
\end{abstract}

Key words: hermeneutical situation, destruction, factic life, formal indicators, categorial intuition

Durante la etapa docente de Marburgo, en pleno periodo de incubación de Ser y tiempo, el pensamiento de Heidegger atravesó por una fase de profundo replanteamiento de algunos temas fundamentales de la fenomenología de Husserl, tales como el de la conciencia, el de la intencionalidad, el de la reducción fenomenológica o el de la intuición categorial. A partir de ese

*El presente trabajo se enmarca en el Proyecto de Investigación PB 96-1144 del Ministerio de Educación y Cultura y refleja parcialmente los resultados de una estancia de investigación en la Universidad de Friburgo durante el semestre de invierno 1999/2000 financiada por la Direcció General de Recerca de la Generalitat de Catalunya (1999BEAI00229). 
momento, la relación Husserl-Heidegger se movió entre la continuidad y la ruptura: continuidad formal y metodológica; ruptura en planteamientos y respuestas a aquellos temas. Quizá el legado más importante de estas primeras lecciones del joven docente Heidegger para el panorama filosófico actual descanse en su honda preocupación metodológica. Un análisis de sus orígenes fenomenológicos permite descubrir a un Heidegger enfrascado en el arduo problema de cómo acceder adecuadamente al ámbito de donación inmediata de la existencia histórica del hombre.

Desde el trasfondo de esta discusión con Husserl, Heidegger somete a análisis la hermenéutica de la facticidad y su propuesta de articulación categorial de la vida humana. Para ello se sirve del instrumental analítico de los indicadores formales con el fin de llegar al corazón mismo de la existencia humana. Los conceptos básicos a los que recurre la hermenéutica filosófica para explicitar reflexivamente la comprensión que la vida tiene de su propio ser y saber cómo se desenvuelve en el mundo reciben en la obra temprana de Heidegger el nombre de 'indicadores formales', lo que en el lenguaje de Ser y tiempo equivale a los existenciarios. Con esta nueva formulación terminológica se busca una alternativa al engorroso término de 'categoría', demasiado lastrado de resonancias epistemológicas. Todos los escritos de la década de los veinte echan mano, de una u otra manera, de la expresión 'indicación formal' (formale Anzeige), si bien cobra un especial protagonismo en las lecciones del semestre de invierno de 1920-1921 Phänomenologie des religiösen Lebens [Introducción a la fenomenología de la religión], y en los cursos sobre Aristóteles de 1921-1922 Phänomenologische Interpretationen zu Aristoteles. Einführung in die phänomenologische Forschung [Interpretaciones fenomenológicas sobre Aristóteles]. ${ }^{1}$

Ahora bien, el hecho de que la vida pueda desplegarse en categorías supone que interviene algo así como lo que la sexta de las Investigaciones lógicas de Husserl llama una intuición categorial. Las diferentes referencias autobiográficas de Heidegger a la "Investigación sexta" son frecuentes y ocupan un lugar destacado en las lecciones de 1925. Por ello parece más que probable que en las categorías de la vida se mantenga todavía vivo algún rescoldo de esa intuición categorial. A partir de este planteamiento el presente trabajo se articula en torno a cuatro ejes. En primer lugar, se recuerda la importancia metodológica que Heidegger concede a la hermenéutica en su tarea de descubrir, de desvelar el sentido originario de la vida, del ser-ahí (1). A continuación se rastrean los antecedentes de los

${ }^{1}$ Cfr. GA 60, §§ 11-13, y GA 61, pp. 16-41, respectivamente. Asimismo encontramos alusiones fragmentarias en la recensión, redactada entre 1919 y 1921, "Anmerkungen zu Karl Jaspers' 'Psychologie der Weltanschauungen'" ["Observaciones a la 'Psicología de las concepciones del mundo' de Karl Jaspers"] (AKJ, pp. 8-11 y 27-33), en el Informe Natorp de 1922 (PIA, pp. 237-239 y 247-249) y en las lecciones de 1929-1930 Die Grundbegriffe der Metaphysik. Welt-Endlichkeit-Einsamkeit [Conceptos fundamentales de la metafísica. Mundofinitud-soledad] (GA 29/30, \& 70).

Diánoia, vol. XLIX, no. 52 (mayo 2004). 
indicadores formales a partir de la comunicación indirecta de Kierkegaard y las expresiones ocasionales de Husserl (2). Seguidamente se pasa a concretar el significado y la función que desempeñan esos indicadores en la articulación categorial de la vida humana (3). Y, por último, se trata de mostrar hasta qué punto Heidegger se alimenta del concepto husserliano de intuición categorial (4).

\section{La hermenéutica como articulación categorial de la vida fáctica}

La hermenéutica, más allá de plasmar un método de interpretación de textos históricos, literarios o sagrados, permite un acceso directo a la vida del hombre, penetrando en sus entramados de significación y articulando la comprensión que la vida tiene de sí misma en cada caso. En otras palabras, ofrece la posibilidad de una interpretación de la facticidad humana, tal como apuntan las lecciones de 1923: "La hermenéutica tiene la tarea de hacer accesible la existencia propia de cada uno, de tratar de rastrear la alienación de la que está afectada. En la hermenéutica se desarrolla para la existencia una posibilidad de llegar a entenderse." ${ }^{2}$ Heidegger recalca que con el concepto de facticidad se pretenden evitar las nociones de 'yo', 'persona', 'ego', 'sujeto' o 'animal rationale', ya que cada una ellas coloca de antemano la facticidad dentro de una determinada región categorial y distorsiona la determinación originaria de la existencia humana en su cuidarse del mundo en general. Con ello se mantiene vivo el interés por una ciencia originaria en la que la vida tenga la oportunidad de darse a conocer a sí misma desde una comprensión inmediata de la realidad que la envuelve de ordinario y de indagar en las raíces históricas que la nutren. Éste es el sentido en el que Heidegger entiende la hermenéutica como autointerpretación de la facticidad.

Con este cambio de perspectiva se pretende romper con el ideal husserliano de una filosofía como ciencia estricta, exenta de presupuestos, transparente y valorativamente neutra. Pasamos así de la conciencia reflexiva husserliana, que de manera intuitiva tiene ante sí su objeto, a lo que Heidegger denomina la 'situación hermenéutica'. Esta situación precede a la mirada; mejor dicho, está indisolublemente presente en ella y forma parte de ella. Toda interpretación se mueve bajo el arco de una triple preestructura formada por un tener (Vorhabe), un ver (Vorsicht) y un concebir previos (Vorgriff) que configura todo proyecto primario de comprensión. ${ }^{3}$ Ningu-

${ }^{2}$ GA 63, § 3, p. 15. Para una reconstrucción interesante y completa del proceso de elaboración de la hermenéutica de la facticidad durante los primeros años docentes de Heidegger en Friburgo remitimos principalmente a Fabris 1997, Herrmann 2000, Kisiel 1993 y Rodríguez 1997. También pueden consultarse Adrián 2001, Segura 1999 y diversos artículos en los volúmenes colectivos de Buren y Kisiel 1994 y Courtine 1996.

${ }^{3}$ Para más detalles sobre la estructura de la precomprensión y del círculo hermenéutico a 
na interpretación es un aprehender sin supuestos de algo dado. La misma hermenéutica, en cuanto fáctica, se mueve esencialmente en la esfera de la comprensión preontológica que la vida humana tiene de su propio ser. En este sentido - como señala acertadamente von Herrmann-, la hermenéutica fenomenológica desarrolla las condiciones de posibilidad de toda investigación ontológica. ${ }^{4}$

El hermeneuta ha de mostrarnos la posibilidad de acceder a la apertura originaria de la vida. El acto filosófico tiene que realizar, ejecutar, ese paso de apropiación de la vida para comprender las cosas. La mirada fenomenológica no se sitúa en otro nivel que el de la vida fáctica misma; filosofía es, como reza el título del presente apartado, autointerpretación de la facticidad. A la filosofía, por tanto, le está reservada la misión de explicitar el sentido del ser de la vida fáctica. No se identifica con la interpretación espontánea que la vida inmediata tiene de sí. De ser así no haría falta la filosofía ni habría necesidad de ninguna ulterior interpretación. Pero lo que se da con la situación es algo más bien indeterminado, que solicita ser indagado y articulado conceptualmente. Con la apropiación de la situación hermenéutica ganamos el horizonte previo en el que se mueven las cosas.

Ahora bien, de entre los horizontes posibles, ¿cuál es el fenomenológicamente más cercano a la vida humana y el que ha de guiar a la hermenéutica de la facticidad? Es una decisión importante la que aquí está en juego; porque "todo radica en que el objeto no sea falsificado de antemano en el primer arranque de la explicación hermenéutica". ${ }^{5}$ Heidegger escoge la situación en la que ya estamos de facto: la actualidad cotidiana, el 'hoy' (das Heute). La interpretación arranca del modo específico como hoy nos vemos a nosotros mismos, esto es, de una comprensión cotidiana de término medio del 'uno' (das Man): "el uno tiene algo ciertamente positivo, no es sólo indicativo de un fenómeno de caída, sino que en cuanto tal manifiesta un modo de la existencia fáctica". ${ }^{6}$ Esto significa que el serahí se mueve en cierto nivel de interpretación públicamente vertebrado que delimita de modo fluctuante sus diferentes maneras de tratar con las cosas del mundo y de comportarse con las otras personas. La apropiación fenomenológica se dirige, pues, a ese discurso público; sin embargo, ese discurso público se presenta bajo modalidades diversas: desde la histórica, política o económica, hasta la filosófica, psicológica o religiosa. ¿Cuál de ellas es la más adecuada? No hay una respuesta clara a esta cuestión. En

ella asociada, consúltese PIA, pp. 237-238 y SuZ, § 45, p. 232 [SyT, p. 252], así como algunos interesantísimos pasajes de Verdad y método de Gadamer, cuya hermenéutica filosófica se mueve precisamente en la estela de estas tempranas lecciones de Heidegger, desarrollando productivamente algunos de sus principales motivos (véase, por ejemplo, Gadamer 1990, pp. 270 y ss).

${ }^{4}$ Cfr. Herrmann 1990, pp. 18-23.

${ }^{5}$ GA 63, § 6, p. 29.

${ }^{6}$ GA 63, § 3, p. 17. 
el contexto del curso de 1923 se señalan dos direcciones interpretativas: la conciencia histórica y la filosofía de la época; pero podrían haber sido otras: por ejemplo, las encuestas sociológicas, el nivel de desarrollo de la ciencia o, como en Durkheim, los índices de suicidio. Nada justifica que en ellas accedamos de manera privilegiada a la situación hermenéutica.

$\mathrm{Al}$ reconocer que en la interpretación pública en la que nos movemos existen elementos que pueden desfigurar, encubrir o desvirtuar nuestra comprensión auténtica de la facticidad, se impone un momento crítico de desmontaje (Abbau) de la orientación previa. En las representaciones colectivas se sedimenta y filtra, consciente e inconscientemente, toda una tradición de normas, valores, imágenes del mundo, roles sociales, etc., que condicionan cualesquiera de nuestras decisiones y acciones. El problema estriba en que la tradición nos transmite en bruto el uso y la aplicación de los conceptos sin una comprensión clara de su sentido. Por eso, el primer paso de toda investigación fenomenológica consiste en reconocer el peso de la tradición y reconocer, en un ejercicio de autorreflexión, los prejuicios con los que opera. Justamente esto es lo que lleva a cabo el desmontaje crítico de la tradición heredada: asumir críticamente — como más tarde señala Gadamer- los prejuicios. ${ }^{7}$ Ese esfuerzo de desmontaje desenmascara los preconceptos operativos en toda interpretación y los devuelve a su origen. Por ello, desmontaje no equivale a destrucción o aniquilación del pasado y de la tradición; más bien encarna un procedimiento básicamente metodológico dirigido a apropiarse el pasado que permite sabernos en deuda con él. El pasado, desde una perspectiva formal, tan sólo suministra una orientación de sentido que la interpretación ha de seguir. La asunción de nuestra imbricación histórica con el pasado debe ayudarnos a comprender cómo la vida de nuestra época está actuando efectivamente en las formas de la conciencia histórica y de la filosofía.

\section{La comunicación indirecta de Kierkegaard y las expresiones ocasionales de Husserl}

La aproximación fenomenológica 'a las cosas mismas' precisa de un lenguaje depurado de las impregnaciones objetivantes de la actitud teórica. El joven Heidegger de las lecciones de 1919 ya andaba preocupado por el problema metodológico de un lenguaje filosófico que le permitiera articular y plasmar directamente la comprensión prerreflexiva que la vida tiene de sí misma. No obstante, ese esfuerzo de transparencia topa con la cuestión de cómo aprehender esa vida en su inmediatez sin incrustarla en una concepción del mundo, sin caer en la objeción de Natorp a Husserl de que toda experiencia, en cuanto expresada en conceptos, se somete a un

${ }^{7}$ Cfr. Gadamer 1990, pp. 296-304. 
proceso de homogeneización que disuelve la particularidad de toda experiencia vivida. ${ }^{8}$ A nuestro juicio, Heidegger entrevé una primera salida a ese problema en la propuesta filosófica de Kierkegaard; en concreto, en su concepción de la comunicación indirecta.

Heidegger aprecia en el método de la comunicación indirecta de Kierkegaard, del que tenía noticia por la lectura del libro de Karl Jaspers Psicología de las concepciones del mundo (1919) y de quien absorbe buena parte de sus interpretaciones, un modelo interesante de aproximación al tema de la existencia humana. ${ }^{9}$ Independientemente de sus connotaciones teológicas, hay que comprender la concepción kierkegaardiana de la existencia desde el horizonte de la discusión con Hegel. En este contexto, la contraposición que Kierkegaard se plantea en el Abschließende unwissenschaftliche Nachschrift (1846) [Postscriptum acientífico definitivo] entre existir y pensar abstractamente, entre pensamiento subjetivo, acientífico y con miras a la individualidad, y pensamiento objetivo, científico y con afán de sistema resulta tremendamente esclarecedora. Este escrito aborda básicamente el problema de cómo puede el hombre concreto establecer una relación correcta con el mensaje de la doctrina cristiana. Un asunto que en el marco de la lógica especulativa de Hegel no ofrece - a los ojos de Kierkegaard - una respuesta satisfactoria, porque concibe el cristianismo como una etapa más del desarrollo del espíritu en su camino hacia la reconciliación absoluta.

El pensador abstracto y sistemático no presta atención al fenómeno de la existencia fáctica, al discurrir aquí y ahora de la vida de cada uno, pues ésta se disuelve en la universalidad atemporal del concepto; en cambio, el pensador subjetivo considera que el devenir temporal forma parte del tejido humano, y se manifiesta explícitamente en todas aquellas ocasiones en las que el individuo se ve obligado a tomar una decisión. Los maestros de la totalidad — comenta Jaspers- dan la espalda a los individuos y ofrecen, como es lógico, envolturas para todos. Los pensadores de la individualidad focalizan sus esfuerzos en el hombre; esto es, apelan a la vida que hay en él mismo y en el otro, estimulando su desarrollo a través de la acción recíproca. ${ }^{10}$ La realidad humana, por tanto, es algo esencialmente inde-

${ }^{8}$ Cfr. GA 56/57, § 20, pp. 110-111.

${ }^{9}$ Véase al respecto la citada recensión "Observaciones a la 'Psicología de las concepciones del mundo' de Karl Jaspers". Al margen de la cuestión de la comunicación indirecta que aquí nos ocupa, resulta interesante comprobar que en el denso libro de Jaspers se hallan otros enfoques de la obra kierkegaardiana presentes en el pensamiento del joven Heidegger. Por ejemplo, la idea de que la vida humana se mueve en la antinomia de lo universal (Hegel) y de lo individual (Kierkegaard), la convicción de que el hombre encarna una unidad paradójica de necesidad y posibilidad (preludio de la condición arrojada de Ser y tiempo) o el concepto de riesgo implícito en todo acto de realización de la vida, es decir, los diferentes grados de manifestación del sí mismo, de la existencia fáctica (véase Jaspers 1967, pp. 487-490, 491500, 507-513 y 533-557, respectivamente).

${ }^{10}$ Cfr. Jaspers 1967, pp. 487-488.

Diánoia, vol. XLIX, no. 52 (mayo 2004). 
terminado, incompleto, en movimiento constante; pero entiéndase esta indeterminación en el sentido positivo de que la existencia queda siempre abierta a constantes procesos de realización, a nuevas posibilidades de acción. La existencia no puede encorsetarse en patrones científicos, no debe cosificarse bajo el signo de la identidad. ${ }^{11}$ Sus diferentes formas de concreción responden más bien al modelo de la creación artística de un poeta - símbolo genuinamente acientífico- capaz de combinar las fuentes de la imaginación y del sentimiento con el pensamiento.

Para Kierkegaard, la filosofía no es capaz de ofrecer soluciones generales. Su función, algo más modesta, se limita a "indicar al ser humano el camino de la ética, de la religión y de la existencia". ${ }^{12}$ Esa indicación es indirecta; es decir, no se pliega sobre la objetividad y la certeza de la ciencia. De ahí la diferenciación que se establece entre los siguientes dos modos de comunicación: uno directo y objetivo, que se concreta en el lenguaje universalista del discurso científico, de los libros de texto, de las enciclopedias o de los sistemas lógicos y cuya meta es conquistar la verdad absoluta; otro indirecto y subjetivo mediante el cual el individuo, el hombre concreto como sujeto responsable de sus actos y persona dotada de un destino intransferible busca algún tipo de explicación al paradójico misterio de la figura humana de Cristo, a saber, la contradicción de que lo universal esté depositado en lo individual. Kierkegaard establece la diferencia absoluta, la inconmensurabilidad insalvable entre la esfera del hombre y la esfera de Dios. Cuanto más alto es el valor de una realidad, más difícil es aprehenderla; la realidad absoluta será, por definición, una incógnita irresoluble para la razón humana, será completamente inaprehensible, incomunicable, al menos de forma directa e inmediata. Sólo el salto de la fe sobre el abismo de la razón permite reconocer a Dios. Y dado que esta verdad no se puede expresar directa y objetivamente, Kierkegaard se limita a 'llamar la atención sobre', 'a tomar nota de' esta situación en un lenguaje personal, acientífico, indirecto, que funciona por medio de seudónimos, epigramas, aporías, anécdotas o ironías.

La comunicación indirecta pretende devolver al lector $\mathrm{u}$ oyente a la verdad subjetiva que reposa en su propia situación histórica concreta. Mas ello sólo es posible después de desprenderse de las aparentes certezas de la vida pública. Se da aquí un doble movimiento. Un primer momento destructivo, de rechazo de las objetividades ideales de un saber absoluto. Obviamente, el enemigo intelectual al que ha de combatir es Hegel; su idealismo es un

\footnotetext{
${ }^{11}$ En esta misma línea de interpretación se mueve la posterior valoración de Heidegger del concepto kierkegaardiano de existencia en las lecciones de 1941 Die Metaphysik des deutschen Idealismus [La metafísica del idealismo alemán] (GA 49, § 10, pp. 19-26).

12 GA 61, p. 82. La misma palabra griega 'hermeneia' significa 'anunciar', 'comunicar', 'indicar', 'poner sobre la pista de algo', 'llamar la atención de alguien', 'dirigir la mirada hacia' (cfr. GA 61, pp. 36, 167, 185; GA 63, §§ 2, 10 у 18).
} 
atentado al núcleo más íntimo de la persona, cuya libertad e individualidad se sacrifican en nombre de la necesidad y la universalidad de la idea. Una vez que nos hemos quitado de encima la pesada losa del sistema especulativo hegeliano, entra en escena un segundo momento constructivo de aproximación a la vida. En Einübung im Christentum (1850) [Ejercitación del cristianismo], Kierkegaard afirma que el momento positivo de la comunicación indirecta consiste en apuntar en la dirección de una concreción de la vida: "Las diferentes proposiciones indirectas, en el mismo sentido de los milagros, sirven para llamar la atención sobre el que presta atención. Éste topa con la contradicción y decide si creer o no." ${ }^{13}$ La verdad se conquista en un ejercicio de apropiación personal. Nunca se la posee enteramente. Siempre se está en camino hacia ella.

La comunicación indirecta crea un estado de intranquilidad; sólo hace problemáticas las cosas, pero sin dar prescripciones, sin enseñar cómo hay que vivir; apela a decisiones concretas sobre el destino personal, una decisión que siempre ha de tomarse sobre varias posibilidades. Sin embargo, esta decisión no es duradera, sino que debe repetirse en cada instante entre 'lo uno o lo otro'. De ahí el valor concedido por Kierkegaard al momento, al kairós de la elección; una observación integrada luego en el programa filosófico de Ser y tiempo sin apenas modificaciones. En definitiva, comunicación indirecta no es sinónimo de máscara o de silencio. Esto sería una técnica empleada exclusivamente por los hombres que se creen superiores. Comunicación indirecta significa que en la búsqueda de claridad y de fórmulas capaces de explicar las paradojas de la vida humana topamos con los límites de nuestra razón y de nuestro lenguaje; significa que todo lo que podemos expresar y decir se limita a lo inesencial, a lo inauténtico, si bien en ello encontramos un portador indirecto de lo esencial, de lo auténtico. En nuestra existencia cotidiana y pública, según la posterior reformulación heideggeriana, late una precomprensión del ser que se va haciendo explícita cada vez en la medida en que avanzamos de la impropiedad de la caída en el uno al estado de propiedad inherente al querer tomar conciencia de esa situación.

La distinción kierkegaardiana entre comunicación directa e indirecta, con sus correspondientes grados de verdad objetiva y subjetiva, es muy similar a la diferencia que Husserl reconoce en la "Investigación primera" entre expresiones objetivas y expresiones ocasionales. ${ }^{14}$ En ciencias naturales, en matemática o en lógica, la significación de una expresión como, por ejemplo, 'existen sólidos regulares' es objetiva y comprendida "sin ne-

\footnotetext{
${ }^{13}$ Kierkegaard 1955, §§ 3, 130.

${ }^{14} \mathrm{Al}$ principio de los años veinte, Heidegger dedicó algunos seminarios a la "Investigación primera" de Husserl, de la que al parecer extrajo el término 'indicación'. Éste es al menos el testimonio de Günther Stern, en aquella época doctorando de Husserl y asistente a las clases de Heidegger (comentado por Buren 1994, pp. 328 y 406, n. 5).
} 
cesidad de tener en cuenta la persona que se manifiesta y las circunstancias de su manifestación". ${ }^{15} \mathrm{El}$ sentido es atemporal y no se ve afectado por la alteración de la situación; permanece siempre idéntico en los diferentes actos. En cambio, las expresiones ocasionales del tipo 'hay pasteles' sólo resultan significativas para el oyente considerando "las efectivas circunstancias de la manifestación". ${ }^{16}$ En este caso, el significado queda vinculado a la situación del sujeto hablante y fluctúa en función de la perspectiva del oyente observador, por lo que nunca está completamente presente en la intuición. La cosa misma se escapa, no hay percepción en el sentido clásico de la presencia plena. Sucede así con los pronombres personales, con los demostrativos y con las locuciones indexicales del tipo 'aquí, 'arriba', 'ayer', 'después', etc. Son expresiones que, en términos de pragmática del lenguaje, sólo se comprenden a partir del contexto de uso. Cuando, por ejemplo, el hablante dice 'yo', el oyente sólo sabe lo que el hablante opina mirando a éste y viendo la situación en la que emite esa expresión. La palabra 'yo' no puede actuar como la palabra 'león', capaz de despertar en sí y por sí misma la representación del león. Únicamente tiene un sentido indicativo, orientador, direccional, como diría Heidegger.

En el uso de expresiones ocasionales entran en juego dos niveles de significación superpuestos: un nivel remite a la función general de la palabra misma 'yo', a la indicación universalmente operativa pero vacía de contenido (significación indicativa); el otro nivel remite a la representación singular que da a conocer al yo mentado en su aquí y ahora concretos (significación indicada). ${ }^{17}$ De ahí que las expresiones ocasionales sean esencialmente ambiguas. En la "Investigación sexta", Husserl clarifica las razones de esa ambigüedad. Ésta obedece al hecho de que la secuencia de la indicación no es la misma para el oyente que para el hablante. Al decir 'aquí, 'en' o 'ella', el hablante conoce de antemano lo indicado con estas expresiones. No así el oyente: si la cosa no cae dentro de su campo visual o en ausencia de la persona designada, sólo alcanza una comprensión imprecisa

${ }^{15} \mathrm{LU}$ II/1, § 26, p. 86 [IL/1, p. 273].

${ }^{16}$ LU II/1, § 26, p. 87 [IL/1, p. 274]. Este riesgo de contingencia y de relativización inherente a la indicación es el que Husserl intenta neutralizar, por todos los medios, en el transcurso de la "Investigación primera". En ella se acomete un análisis fenomenológico preciso del signo desde su vertiente básicamente ideal como unidad objetiva y evidente de significado que no es susceptible de modificaciones en función de las circunstancias; en palabras de Derrida, se pone a prueba la posibilidad de la repetición de un acto productor. En este contexto es en el que cabe situar el antagonismo que Husserl establece entre alusión indicativa (Hinweis) y demostración deductiva (Beweis). La demostración remite a un encadenamiento evidente y apodíctico de regularidades ideales que unen los contenidos de los objetos ideales, mientras que la indicación encadena motivaciones de orden empírico y contingente incrustadas siempre en un hinc et nunc concreto (cfr. Derrida 1995, pp. 42ss y 69-73). Resulta obvio que en nombre de la pretensión científica de las Investigaciones lógicas, enemiga de todo historicismo y psicologismo de corte relativista, se apueste abiertamente por el postulado de la idealidad.

${ }^{17}$ Cfr. LU II/1, § 26, pp. 98-100 [IL/1, pp. 273-275]. 
y general de la situación de habla. El verdadero objetivo de la expresión no reside en esta representación general, sino en la intención directa hacia el objeto respectivo. ${ }^{18} \mathrm{~A}$ través de ella se logra dar un sentido pleno y auténtico a la significación. Éste es el uso husserliano de 'indicación' que tan notablemente está presente en Heidegger: la significación indicativa vaga sin rumbo, permanece vacía si no es plenificada; ${ }^{19}$ en palabras de Heidegger, la indicación formal carece de sentido si no está referida a una situación concreta.

La serie de impersonales que Heidegger comienza a emplear desde 1919, tales como 'es gibt' (hay o se da), 'es weltet' (mundea) o 'es ereignet' (se apropia), son justamente expresiones ocasionales que operan al estilo de categorías indicativas de una situación. El mismo Husserl ya mostraba esto de la mano del siguiente ejemplo:

Nadie entenderá la frase "hay pastel" ("es gibt Kuchen") de la misma manera que la proposición matemática "hay cuerpos regulares". En el primer caso no quiere decir que en general existan pasteles, sino que aquí $y$ ahora hay pastel para el café. La frase "llueve" ("es regnet") tampoco significa que llueva en general, sino que llueve ahora y ahí afuera. ${ }^{20}$

En este sentido, el término cotidiano 'indicación' viene a significar 'noticia' o 'anuncio' de un acontecimiento único que se produce en un hinc et nunc determinado, como el nacimiento de una persona, la boda de un pariente o el funeral de un amigo. Los giros heideggerianos de 'algo', 'ser-ahí', 'facticidad', 'haber-sido', etc., vienen a ser expresiones ocasionales cuya función indicativa es mantener abierta la comprensión situacional de la existencia humana. En el curso de 1920-1921, Heidegger empezó a mostrar cómo esas expresiones se extraen de la vida fáctica y se transcriben en indicadores formales.

Los indicadores formales también tienen una doble dirección: una negativa y destructiva; otra positiva y constructiva. En el primer caso, existe el riesgo de permanecer estancado en una concepción atemporal y estática de la vida, refugiándonos en un apaciguador sistema filosófico; en el segundo caso, en cambio, la indicación formal invita a abrirse a diferentes contextos vitales, ofreciendo a la vida diferentes modos de realización. ${ }^{21}$ Sin embargo, Heidegger reconoce que "esta situación no es ni mucho menos la costa salvadora, sino que más bien empuja a saltar al bote en movimiento; y

${ }^{18}$ Cfr. LU II/2, § 5, pp. 555-556 [IL/2, pp. 614-615].

${ }^{19}$ Me he permitido sustituir el término 'signo', propuesto por García Morente y Gaos para traducir la palabra alemana 'Anzeige', por el de 'indicación', con el fin de resaltar aún más la proximidad de Heidegger con el texto de Husserl.

${ }^{20}$ LU II/1, § 27, p. 92 [IL/1, pp. 277-278].

${ }^{21}$ Cfr. GA 61, pp. 66-67. 
ahora sólo queda asir el cabo de la vela y colocarse a favor del viento". ${ }^{22}$ Cuando se desea saltar al terreno de la facticidad, uno tiene que saber sortear escollos de este tipo. Los indicadores formales nos proporcionan una brújula para orientarnos en el insondable océano de la existencia humana.

La filosofía huye de sistemas tranquilizadores, de soluciones estereotipadas, de tradiciones consagradas para zambullirse en la corriente fáctica de la vida. Siempre está en camino, abierta a nuevas preguntas, dispuesta a cambiar el rumbo, en constante proceso de realización. De ahí que "siempre que se comprende la indicación formal como una proposición general, inamovible y se construyen con ella deducciones dialécticas se incurre en un malentendido". ${ }^{23}$ Heidegger, a diferencia de Kierkegaard, no lanza sus dardos tanto contra Hegel como contra lo nocivo del esquema sujetoobjeto, que fatalmente acaba por reconducir cualquier tema a la parcela de la teoría del conocimiento. La existencia con su singularidad, su problematicidad, su riesgo infinito no tiene cabida en el cerco del sistema. En las aisladas y fragmentarias concreciones del estatuto de los indicadores formales, lo formal apunta siempre en una dirección, aporta un modo de abordar el sentido sin introducir contenido alguno, sirve de punto de partida, invita a la acción. Ahora bien, ¿qué sentido da Heidegger a lo formal?, ¿hacia dónde remite la indicación?

\section{El significado y la función de los indicadores formales}

En los cursos de 1920-1921, Introducción a la fenomenología de la religión, se recuerda que el sentido de la indicación formal se remonta a la diferencia husserliana entre generalización y formalización, tal como se aborda al final de los Prolegómenos a la lógica pura y en el parágrafo 13 de Ideas. ${ }^{24}$ En este último texto, Husserl señala que la generalización se aplica dentro de un determinado campo de experiencia, y asciende progresivamente de lo concreto a lo general. Por ejemplo, pasamos de rojo a color y de color a cualidad sensible, de alegría a sentimiento y de sentimiento a vivencia. La formalización, en cambio, está libre de la referencia al contenido material y se pliega sobre las estructuras lógicas y formales que ya siempre están presupuestas en el conocimiento. Cuando decimos 'La piedra es un objeto', empleamos una categoría formal que no pertenece a la naturaleza de la cosa. Las categorías formales, como 'objeto', 'esencia', 'pluralidad', 'relación',

22 GA 61, p. 37.

${ }^{23}$ GA 63, § 16, p. 80.

${ }^{24}$ Cfr. GA 60, § 12, p. 57. Para el tema de los indicadores formales de la existencia humana, véanse, entre otras, las aportaciones de Buren 1994, pp. 324-341; Dahlstrom 1994, pp. 775797; Dijk 1991, pp. 89-100; Imdahl 1997, pp. 142-174; Kalariparambil 1999, pp. 127-139; Kisiel 1996, pp. 205-210; Oudemans 1990, pp. 86-95; Pöggeler 1991, pp. 82-89; Rodríguez 1997, pp. 155-187, y Streeter 1997, pp. 413-430. 
etc., se aplican directa e independientemente del contenido, del 'qué'. Lo formal no reside en la cosa, no forma parte de su contenido como, por ejemplo, la superficie en la piedra o el color en la silla. ${ }^{25}$

En un pasaje del mencionado curso de 1920-1921, Heidegger se desmarca explícitamente de la pretensión husserliana de una ontología puramente analítica, de una mathesis universalis: "Indicación formal nada tiene que ver con lo universal, pues cae fuera del ámbito de lo teorético." 26 Precisamente todos los indicadores formales que Heidegger va descubriendo, tanto en su interpretación de las epístolas paulinas ('cuidado', 'conciencia' o 'uno') como en la de los escritos aristotélicos ('phronesis', 'praxis' o 'proairesis'), se caracterizan por este enconado esfuerzo de relativización de la teoría. La indicación formal no comparte en absoluto el interés de la teoría por ordenar y catalogar los entes. No podemos olvidar que la hermenéutica arranca de una orientación previa de la que forma parte un determinado sentido del ser de la vida fáctica. El ser-ahí no acontece sin más como un puro estar ahí, como un conjunto de propiedades. Su existencia está condicionada por el factum de un tener que ser, de un ocuparse de su propio ser. Lo decisivo en el planteamiento existenciario de Heidegger es que los rasgos que constituyen su esencia han de ser realizados, ejecutados, llevados a la práctica. El ser precomprendido en la orientación previa no es una esencia dotada de contenido material o eidético, sino un modo, un 'cómo' determinado de ser. La autorreferencia de la vida adquiere en Heidegger un sentido activo y no meramente cognoscitivo, tiene que ver más con el hacerse que con el reconocerse. Para decirlo de un modo gráfico: existiendo nos jugamos el tipo. Salirse del círculo no es posible, pues ya estamos comprometidos con nosotros mismos. No jugarse el tipo ya es una modalidad de existencia. Heidegger expresa esta inevitable autorreferencia que constituye a la existencia, diciendo que el hombre es un ente al que en su ser 'le va' su ser mismo.

El sentido de una indicación formal no está referido a una entidad objetiva dada cuyo eidos haya de ser captado, sino que significa literalmente seguir una indicación, tomar una dirección. Su vaciedad formal consiste en que sólo señala hacia dónde, sin presentar entidad alguna: "Precisamente el contenido, las determinaciones que se dan del objeto no deben convertirse como tales en tema, sino que la comprensión que las capta ha de seguir la dirección indicada de sentido." ${ }^{27}$ Así, en el mismo acto en el que el hombre realiza su vida está realizando su ser. No hay dos entidades diferentes, la vida y la realización; más bien nos hallamos ante un único acto que se completa en la ejecución del propio vivir.

${ }^{25}$ Cfr. Ideen I, § 13, pp. 32s [Ideas, pp. 28s].

${ }^{26}$ GA $60, \S 12$, p. 59.

27 GA 61, p. 32.

Diánoia, vol. XLIX, no. 52 (mayo 2004). 
En las escasas páginas que Heidegger dedica a la cuestión de los indicadores formales en las lecciones del semestre de invierno de 1929-1930, Conceptos fundamentales de la metafísica. Mundo-finitud-soledad, se señala que apuntan a un modo de concreción de la existencia individual del hombre sin transmitir contenido alguno. ${ }^{28}$ Heidegger nombra como ejemplos de indicación formal los términos 'muerte', 'resolución', 'historia' o 'existencia'. ¿Qué implica, sin embargo, poseer una comprensión formalindicativa de un concepto como el de 'existencia'? Realizar propiamente la existencia es una indicación que cada uno debe comprender e interpretar por sí mismo. Este postulado no es abstracto, ni mucho menos, sino que encierra un sentido eminentemente concreto que apunta en la dirección de la situación fáctica en la que nos encontramos en cada caso.

La indeterminación material de los conceptos filosóficos no es tanto un síntoma de insuficiencia como un signo de su verdadero potencial: "El contenido significativo de estos conceptos [los indicadores formales] no mienta directamente aquello a lo que se refiere, sólo ofrece una indicación, un indicio que exhorta a quien comprende esta indicación a llevar a cabo una transformación de su existencia." ${ }^{29}$ La pretensión originaria de esos conceptos consiste en mostrar al individuo la situación concreta en la que vive, pero sin prescribir axiológicamente su contenido. Los indicadores formales son conceptos básicamente dinámicos, "inician metódicamente una actividad hermenéutica que suministra a la filosofía un punto de partida. Los indicadores formales, recuerda Heidegger, no deben ser comprendidos como nexos normativos, lo indicado no debe ser hipostasiado." ${ }^{30}$ Los conceptos hermenéuticos simplemente nos colocan ante el momento de la decisión, mas la decisión concreta queda en el aire. Los conceptos no son esquemas de acción prefijados; más bien diseñan diferentes posibilidades de ser de la vida.

Su comprensión es meramente vacía. El comprender una categoría hermenéutica no dice nada acerca de cuál es su intuición impletiva correspondiente, porque no remite a objeto alguno. En este punto Heidegger muestra sus reservas críticas frente al concepto husserliano de evidencia como plenificación intuitiva de una significación vacía por medio de una percepción correspondiente y plenamente adecuada. La extracción de las categorías es un acto hermenéutico entregado al sentido de los fenómenos. Aquí no tiene cabida la noción de un acto intencional reflexivamente neutro. La creencia en la evidencia, la creencia de que las cosas se dan originariamente a la mirada del yo es altamente peligrosa por cuanto parece dispensar de todo esfuerzo de apropiación. ${ }^{31} \mathrm{El}$ tono crítico va dirigido a la creencia de que

\footnotetext{
${ }^{28}$ Cfr. GA $29 / 30$, § 70, p. 429.

${ }^{29}$ GA $29 / 30$, § 70, pp. 429-430.

${ }^{30}$ GA 59, § 10, p. 85.

${ }^{31}$ Cfr. GA 63, § 9, p. 46.
} 
la evidencia capta el sentido por el mero hecho de que la cosa esté inmediatamente ahí delante. La presencia de la cosa no nos exime de la tarea de la comprensión. Aún menos si tenemos en cuenta la tendencia estructural al encubrimiento de la vida, lo que aumenta considerablemente las posibilidades de una intelección teorética del objeto. Aquí se plantea la cuestión, nada baladí para la hermenéutica, de si toda autocomprensión de la vida es sinónimo de una comprensión originaria. Hay que evitar reintroducir la representación objetivante de la evidencia como acto intencional dirigido a una objetividad determinada.

La indicación formal únicamente nos remite a la realización del modo de ser por ella indicado, bien como 'ser-en-el-mundo', como 'uno', 'angustia', etc. ¿Cómo surgen, entonces? Por medio de la intuición hermenéutica, esto es, de la evidencia prerreflexiva que la vida tiene de sí misma, cooriginaria con el despliegue de la existencia, ni anterior ni posterior al propio acto de vivir. Por eso Heidegger sostiene lo siguiente:

las categorías no son nada inventado o una sociedad autónoma de esquemas lógicos, sino que de manera originaria viven en la vida misma; en la vida, "formando" vida. Tienen su propio modo de acceso, que en nada es ajeno a la propia vida, como si cayera sobre ella desde fuera, sino que precisamente es el modo señalado en que la vida viene a sí misma. ${ }^{32}$

Las categorías de la vida son la comprensión que, expresada conceptualmente, posee la vida de sí misma. El carácter indicativo y formal de la categoría muestra que entender el sentido pasa por la realización de las acciones indicadas: "un 'concepto' no es un esquema, sino una posibilidad de ser". ${ }^{33}$ Precisamente el significado de la palabra hermeneuein recoge ese doble movimiento de comprensión y comportamiento: ambos se ejecutan en el mismo acto. De ahí que las categorías hermenéuticas sean un modo de ser de la misma facticidad.

\section{El trasfondo de la intuición categorial}

Los indicadores formales o las categorías de la vida fáctica sirven para expresar la autocomprensión que la vida tiene de sí. Pero el hecho mismo de que la vida pueda explicitarse en categorías invita a pensar que en ella se da algo así como lo que las Investigaciones lógicas llaman una intuición categorial. Las referencias de Heidegger a la "Investigación sexta", y en concreto a la cuestión del ser que aflora en el descubrimiento de la intuición categorial, son frecuentes y ocupan un lugar destacado en las lecciones del semestre de verano de 1925, Prolegomena zur Geschichte des Zeitbegriffes

32 GA 61, p. 88.

33 GA 63, § 3, p. 16. 
[Prolegómenos a la historia del concepto de tiempo]. ${ }^{34}$ Por ello es más que probable que en las categorías de la vida, que justamente expresan su ser, encontremos algún rastro de la intuición categorial.

La investigación en cuestión plantea la siguiente pregunta: ¿cómo dar cumplimiento a los momentos intencionales de las formas categoriales? Tomemos como ejemplo la proposición 'la hoja de papel es blanca'. En ella hallamos que las significaciones 'hoja', 'papel' y 'blanco' pueden ser plenificadas por la correspondiente intuición sensible. Pero ¿qué sucede con las palabras 'la', 'de' y 'es'? ¿Pueden llegar a ser vistas o percibidas? Evidentemente, no. Por tanto, hallamos en la proposición un excedente de intenciones que no puede ser cubierto por la simple percepción. ${ }^{35}$ Los correlatos objetivos de las formas categoriales, por tanto, no son momentos reales. El 'es' de la cópula, pero también todas las palabras que expresan constantes lógicas, como 'y', 'entonces', 'porque', 'donde', etc., no tienen su equivalente en el contenido intuitivo de la percepción; resulta imposible dar con un correlato objetivo en los actos de percepción.

De este modo se plantea la pregunta de cuál es el origen del concepto de ser y, por extensión, el de las restantes categorías. Existe la posibilidad, como sostiene Locke, de colocar el origen en la percepción interna como rendimiento inmanente de la reflexión. Pero si miramos prefenomenológicamente la conciencia, objeta Husserl, sólo topamos con procesos psíquicos y no con las formas categoriales. El ser, y en general lo categorial, es algo objetivo, que tiene su cumplimiento en determinados actos. Cada objeto tiene su peculiar modo de darse. Resulta un error grave el tratar unos objetos como si tuvieran el modo de darse de otros; por ejemplo, pretender fundar los actos de la lógica en la percepción de los sentidos. Los actos en los que se nos transmiten verdades matemáticas son distintos de aquellos en los que se nos da una mesa, un perro o una persona. Yo entiendo ' $a^{2}-b^{2}=(a+b)(a-b)$ ' de modo distinto de como veo la mesa. Esta distinción entre actos de intuición sensible y actos de intuición categorial desempeña un papel esencial en la fenomenología husserliana. En la intuición sensible, "el objeto, que se constituye de modo simple en el acto de la percepción, es aprehendido directamente o está presente en persona. Con esto queremos decir que el objeto es un objeto inmediatamente dado." ${ }^{36}$ En la percepción sensible, la cosa externa aparece de golpe y en una sola

\footnotetext{
${ }^{34}$ Entre otras, el escrito autobiográfico "Mein Weg in die Phänomenologie" ["Mi camino en la fenomenología"] (ZSD, p. 86), el seminario de Zähringen (VS, pp. 116ss) y, sobre todo, el extenso estudio que dedica al tema en las mencionadas lecciones de 1925 (GA 20, § 6, pp. 63-98). De entre la extensa producción bibliográfica dedicada al tema de la relación Husserl-Heidegger y, en concreto, al de la cuestión de la intuición categorial nos limitamos a los trabajos de Bernet (1988), Buren (1990), Crowell (1997), Held (1989), Herrmann (1981), Herrmann (2000), Marion (1989), Volpi (1988) y Watanabe (1993).

${ }^{35} \mathrm{Cfr}$. LU II/2, § 40, p. 660 [IL/2, p. 695].

${ }^{36} \mathrm{LU}$ II/2, §46, p. 674 [IL/2, p. 705].
} 
dirección. A pesar de las innumerables propiedades particulares que podamos descubrir en una consideración ulterior de la cosa, ésta aparece en el acto de percepción como una unidad simple. ${ }^{37}$

Ahora bien, todo acto simple de percepción puede funcionar como acto primario en el que se fundan otros nuevos y dar pie a nuevas objetividades, pero de tal suerte que remitan a los actos fundantes. ${ }^{38}$ Justamente esos actos en los que aparece una objetividad nueva son los que Husserl designa con el nombre de 'intuición categorial'. Lo más interesante que debemos retener aquí es que se trata de un acto fundado, o sea, de un acto que no puede mostrar su objetividad si no es en alusión a lo mostrado en otro acto simple. Esta conclusión encierra un aspecto importante para nuestro tema: la formación categorial no implica una transformación real del objeto. El objeto mostrado en la percepción no se ve para nada afectado por la nueva objetividad emergente en la intuición categorial. Los nuevos objetos que crean las formas categoriales no son objetos en sentido primario, no moldean ni dan forma en el sentido del alfarero. En otro caso, lo dado primitivamente en la percepción sensible sería modificado en su propia objetividad. De ahí que las formas categoriales dejen intactos los objetos primarios. ${ }^{39}$

En la intuición categorial, el objeto aparece en una nueva forma de aprehensión que manifiesta explícitamente su realidad. En sintonía con Husserl, Heidegger estima que la intuición categorial posibilita el aparecer de la objetividad de los objetos y con ella la comprensión explícita de su realidad. A este respecto, el texto de Prolegómenos a la historia del concepto de tiempo resulta concluyente:

Por el camino de la comprensión de aquello que está presente en la intuición categorial se puede aprender a ver que la objetividad de un ente no se agota en lo que se determina como realidad [entendida aquí en sentido estricto como el objeto de una percepción sensible]; también se aprende a ver que, en sentido amplio, la objetividad u objetualidad es mucho más rica que la realidad de una cosa, más aún, que la realidad de una cosa en su estructura sólo se comprende desde la plena objetividad del ente simplemente percibido. ${ }^{40}$

La interpretación heideggeriana de la intuición categorial como momento constitutivo de la aprehensión del ente en sí mismo pone de manifiesto sus esfuerzos por evitar el punto de vista trascendental de Husserl. ¿Cómo? Retirando el ser del ámbito subjetivo y ubicándolo en el ámbito objetivo de nuestra comprensión del mundo. Heidegger no ve en las categorías un modo de delimitar las diferentes regiones del ser; más bien ve en ellas

${ }^{37}$ Cfr. LU II/2, § 47, p. 677 [IL/2, p. 707].

${ }^{38} \mathrm{Cfr}$. LU II/2, § 46, p. 675 [IL/2, p. 705].

${ }^{39} \mathrm{Cfr}$. LU II/2, § 61, pp. 714-715 [IL/2, pp. 734-735].

${ }^{40}$ GA 20, § 6, p. 89. 
proyectos que anticipan y guían nuestra comprensión de los objetos dentro de su respectiva región ontológica; o, lo que es lo mismo, las categorías son, ante todo, anticipaciones que nos permiten operar en un contexto dado, en un espacio de iluminación, en una apertura previa del ser, posibilitando así una primera comprensión de los fenómenos que se dan en ese ámbito de sentido ya siempre descubierto y a nuestra disposición.

A partir de este momento, el ser puede convertirse en fenómeno: algo que aparece, que se muestra en un ámbito originario de sentido no modificado por el esquema sujeto-objeto. Para Heidegger, resulta decisivo que ese ámbito categorial quede desvinculado de todo lazo subjetivo, que no obedezca a ningún acto de reflexión interna de la conciencia. "'Ser', 'y', 'es', 'esto', 'uno', 'entonces' no están formados a la medida de la conciencia, sino que son correlatos de determinados actos. [...] Los actos categoriales constituyen una nueva objetividad. 'Constituir' no significa producir [...] sino dejar ver el ente en su objetividad." 41 Sobre esta base se puede plantear la cuestión del significado del ser, de lo que es comprendido con la palabra 'ser'. A juicio de Heidegger, Husserl no pudo dar con el sentido del ser porque lo comprende como dado a la intuición y no como horizonte de iluminación y desvelamiento de los entes. Con todo, en el Protocolo de un seminario sobre la conferencia de 'Tiempo y ser' se reconoce abiertamente que la intuición categorial abona adecuadamente el terreno para cultivar la pregunta por el sentido del ser. ${ }^{42}$ La clave de Husserl, opina Held, reside en el descubrimiento de que lo categorial posee el carácter de una predonación transubjetiva que no sólo facilita la manifestación intencional de los objetos, sino que también abriga la posibilidad de un análisis fenomenológico de esa manifestación. ${ }^{43}$ Lo que realmente cautiva al joven Heidegger es la oportunidad de concebir el 'ser' como un fenómeno de la experiencia vivida y susceptible de ser explicitado categorialmente.

El problema de Husserl estriba en que su caracterización del ser queda restringida al campo específico de la teoría. El sentido básico que se le atribuye aquí es el de ser-objeto, ser-cosa, realidad o naturaleza. ${ }^{44}$ Husserl se ha limitado, a juicio de Heidegger, a adoptar la idea tradicional de ser como cosa a la vista, olvidándose de discutir explícitamente la cuestión de su significado. La intención de Heidegger se cifra en reconducir el análisis fenomenológico al mundo de la vida originaria. Esta tarea ya la había iniciado Dilthey al extraer la noción husserliana de la objetividad intencional

${ }^{41}$ GA 20, § 6, pp. 79 y 97.

${ }^{42}$ Cfr. VS, p. 116.

${ }^{43}$ Cfr. Held 1989, p. 112. En términos del Heidegger tardío, lo categorial posibilita la aparición de los entes, el darse intencional en general y, por ello, funda la dimensión de la patencia en cuya luz el ente es cognoscible e inteligible por primera vez (cfr. VS, pp. 116 y ss). En este sentido, lo categorial cumple una doble función: como ratio essendi, descubre el ente, y como ratio cognoscendi, permite conocerlo.

${ }^{44}$ Cfr. GA 56/57, § 17, p. 87; GA 61, pp. 91-92; GA 20, § 6, p. 83. 
de su contexto lógico y trasplantarla a la esfera vital del mundo práctico y cultural. En sintonía con Dilthey, Heidegger amplía las posibilidades de apertura más allá del campo estrictamente científico del ego trascendental husserliano, dando entrada a los contextos históricos, sociológicos o cotidianos. En este cambio de perspectiva podemos advertir dos momentos esenciales de la apropiación crítica heideggeriana de Husserl: por un lado, la noción de ser es repensada en términos de significado entroncado en el mundo práctico de la vida cotidiana; por otro lado, el método teórico de la intuición universal, excesivamente apegado al horizonte de la objetividad, se sustituye por el de la intuición hermenéutica de raigambre heideggeriana. Con él se busca aprehender originariamente la precomprensión del ser que reposa en la vida concreta.

La posición reflexiva de la percepción interna ya no conserva en el joven Heidegger ningún estatuto de privilegio. La comprobación de las categorías sólo puede llevarse a buen puerto partiendo de la evidencia prerreflexiva que la vida tiene de sí misma. El origen de los indicadores formales se encuentra, por tanto, en la comprensión originaria que la vida tiene de sus estructuras. Esa comprensión ya no obedece a los dictámenes metodológicos del rigor científico, sino que constituye el movimiento básico de la existencia humana. En este sentido, la filosofía da la espalda a las esencias intemporales. Heidegger considera que su competencia se limita a ofrecer indicaciones formales que apuntan en la dirección de las cosas mismas. Pero éstas - esencialmente fácticas, históricas y temporales- exigen un proceso de reapropiación constante. En definitiva, nos hallamos ante un pensar desde Husserl contra Husserl en nombre de un inicio radical y de un retorno a las cosas mismas. Aplicar radicalmente el lema husserliano exige una crítica interna de la fenomenología de la conciencia pura para salvaguardar la prioridad del ser. La ontología emergente perfora las estructuras lógicas de la fenomenología y la autodonación del ser acaba imponiéndose sobre la productividad reflexiva de la conciencia. El camino que recorre el joven Heidegger conduce, por tanto, desde la lógica husserliana de la subjetividad transcendental hasta la ontología fundamental del ser-en-el-mundo del ser-ahí.

\section{BIBLIOGRAFÍA}

Las citas y las referencias a los escritos de Heidegger se realizan íntegramente a partir de la traducción de los textos originales de las Obras Completas (Gesamtausgabe) consignados a continuación. Para los volúmenes de la Gesamtausgabe utilizo la fórmula abreviada GA, seguida del número del volumen, del parágrafo y de la página correspondientes. Para las referencias a otros textos de Heidegger remito a la lista de abreviaturas. En el caso de Ser y tiempo, así como de los textos de Husserl Investigaciones lógicas e Ideas I, indico, tras la referencia de la versión alemana, la correspondiente a la traducción castellana. Las restantes alusiones a la bibliografía 
secundaria se limitan a señalar el apellido del autor, el año de publicación y las páginas que correspondan en cada caso.

1. Lista de abreviaturas

GA 9 Wegmarken

GA $20 \quad$ Prolegomena zur Geschichte des Zeitbegriffes

GA 29/30 Die Grundbegriffe der Metaphysik. Welt-Endlichkeit-Einsamkeit

GA 49 Die Metaphysik des deutschen Idealismus (Schelling)

GA 56/57 Zur Bestimmung der Philosophie

GA $59 \quad$ Phänomenologie der Anschauung und des Ausdruckes

GA 60 Phänomenologie des religiösen Lebens

GA 61 Phänomenologische Interpretationen zu Aristoteles.

Einführung in die phänomenologische Forschung

GA 63 Ontologie. Hermeneutik der Faktizität

Otros escritos de Heidegger

$\begin{array}{ll}\text { AKJ } & \begin{array}{l}\text { "Anmerkungen zu Karl Jaspers' 'Psychologie der Weltanschau- } \\ \text { ungen'” } \\ \text { "Phänomenologische Interpretationen zu Aristoteles. Anzeige } \\ \text { der hermeneutischen Situation" }\end{array} \\ \text { PIA } & \begin{array}{l}\text { Sein und Zeit [Ser y tiempo] } \\ \text { Vier Seminare }\end{array} \\ \text { SuZ [SyTh } & \text { Vur Sache des Denkens }\end{array}$

Obras de Husserl

LU II/1 [IL/1] Logische Untersuchungen (I-V Untersuchung) [Investigaciones lógicas, 1]

LU II/2 [IL/2] Logische Untersuchungen (VI Untersuchung) [Investigaciones lógicas, 2]

Ideen I [Ideas] Ideen zu einer reinen Phänomenologie und phänomenologischen Philosophie [Ideas relativas a una fenomenología pura y una filosofía fenomenológica]

2. Textos de Heidegger por orden cronológico de elaboración

Die Idee der Philosophie und das Weltanschauungsproblem (Primeras lecciones de Friburgo del semestre de posguerra de 1919), en Zur Bestimmung der Philosophie, Vittorio Klostermann, Fráncfort del Meno, 1987, pp. 3-117 (GA 56/57).

Phänomenologie der Anschauung und des Ausdruckes (Primeras lecciones de Friburgo del semestre de verano de 1920), Vittorio Klostermann, Fráncfort del Meno (GA 59), 1993.

"Anmerkungen zu Karl Jaspers' 'Psychologie der Weltanschauungen'” (recensión 
redactada entre los años 1919 y 1921), en Wegmarken, Vittorio Klostermann, Fráncfort del Meno, 1976, pp. 1-44 (GA 9).

Phänomenologie des religiösen Lebens (Primeras lecciones de Friburgo de los semestres de invierno de 1920-1921 y de verano de 1921), Vittorio Klostermann, Fráncfort del Meno, 1995 (GA 60).

Phänomenologische Interpretationen zu Aristoteles. Einführung in die phänomenologische Forschung (Primeras lecciones de Friburgo del semestre de invierno de 1921-1922), Vittorio Klostermann, Fráncfort del Meno, 1985 (GA 61).

"Phänomenologische Interpretationen zu Aristoteles. Anzeige der hermeneutischen Situation" (Informe Natorp 1922), Dilthey-Jahrbuch, vol. 6, 1989, pp. 237274. [Versión en castellano: Interpretaciones fenomenológicas sobre Aristóteles. Indicación de la situación hermenéutica, trad. Jesús Adrián, Trotta, Madrid, 2002.]

Ontologie. Hermeneutik der Faktizität (Primeras lecciones de Friburgo del semestre de verano de 1923), Vittorio Klostermann, Fráncfort del Meno, 1988 (GA 63). [Versión en castellano: Ontología. Hermenéutica de la facticidad, trad. Jaime Aspiunza, Alianza Editorial, Madrid, 1999.]

Prolegomena zur Geschichte des Zeitbegriffes (Lecciones de Marburgo del semestre de verano de 1925), 2a. ed., Vittorio Klostermann, Fráncfort del Meno, 1988 (GA 20).

Sein und Zeit (1927), 16. ed., Tubinga, Max Niemeyer, 1987. [Versión en castellano: Ser y tiempo, trad. Jorge Eduardo Rivera, Universitaria, Santiago de Chile, 1998.]

Die Grundbegriffe der Metaphysik. Welt-Endlichkeit-Einsamkeit (Lecciones de Friburgo del semestre de invierno de 1929-1930), Vittorio Klostermann, Fráncfort del Meno, 1983 (GA 29/30).

Die Metaphysik des deutschen Idealismus (Schelling) (Lecciones de Fribugo del semestre de verano de 1941), Vittorio Klostermann, Fráncfort del Meno, 1991 (GA 49).

"Mein Weg in die Phänomenologie" (1963), en Zur Sache des Denkens, 2a. ed., Max Niemeyer, Tubinga, 1976, pp. 81-90.

Vier Seminare (Seminarios de Le Thor de 1966, 1968 y 1969 y Seminario de Zähringen de 1973), Vittorio Klostermann, Fráncfort del Meno, 1977 [VS].

\section{Bibliografía secundaria}

Adrián, J., 2001, "Der junge Heidegger und der Horizont der Seinsfrage", Heidegger Studien, vol. 17, pp. 93-116.

Bernet, R., 1988, "Transcendence et intentionalité: Heidegger et Husserl sur les prolégomènes d'une ontologie phenoménologique", en Volpi 1988, pp. 195-216.

Buren, J., 1994, The Young Heidegger. Rumor of the Hidden King, Indiana University Press, Bloomington e Indianápolis.

__ 1990, "The Young Heidegger and Phenomenology", Man and World, vol. 23, pp. 239-272.

Buren, J. y T. Kisiel (comps.), 1994, Reading Heidegger from the Start. Essays in His Earliest Thought, State University Press of New York, Albany. 
Courtine J.-F. (comp.), 1996, Heidegger 1919-1929. De l'Herméneutique à la métaphysique du Dasein, J. Vrin, París.

Crowell, S.G., 1997, "Ontology and Transcendental Phenomenology between Husserl and Heidegger", en B. Hopkins (comp.), Husserl in Contemporary Context: Prospects and Projects for Phenomenology, Kluwer Academic Press, Dordrecht, pp. 13-36.

Dahlstrom, D., 1994, "Heidegger's Method: Philosophical Concepts as Formal Indications", Review of Metaphysics, vol. 47, pp. 775-797.

Derrida, J., 1995 (1967), La voz y el fenómeno. Introducción al problema del signo en la fenomenología de Husserl, 2a. ed., trad. y prol. Francisco Penalver, Pre-textos, Valencia.

Dijk, R.J.A., 1991, "Grundbegriffe der Metaphysik. Zur formal-anzeigenden Struktur der philosophischen Begriffe bei Heidegger", Heidegger Studien, vol. 7, pp. 89-100.

Fabris, A., 1997, "L'ermeneutica della fatticità' nei corsi friburghesi del 1919 al 1923", en F. Vopli (comp.), Heidegger, Laterza, Roma, pp. 57-106.

Gadamer, H.-G., 1990 (1960), Wahrheit und Methode, 6a. ed., J.C.B. Mohr, Tubinga. [Versión en castellano: Verdad y método, trad. Ana Agud y Rafael de Agapito, 3a. ed., Sígueme, Salamanca, 1988.]

Held, K., 1989, "Heidegger und das Prinzip der Phänomenologie”, en A. GethmannSiefert y O. Pöggeler (comps.), Heidegger und die praktische Philosophie, Suhrkamp, Fráncfort del Meno, pp. 111-139.

Herrmann, F.-W., 2000, Hermeneutik und Reflexion. Der Begriff der Phänomenologie bei Husserl und Heidegger, Vittorio Klostermann, Fráncfort del Meno.

—_, 1990, Wege und Methode. Zur hermeneutischen Phänomenologie des seinsgeschichtlichen Denkens, Vittorio Klostermann, Fráncfort del Meno.

—_, 1981, Der Begriff der Phänomenologie bei Husserl und Heidegger, Vittorio Klostermann, Fráncfort del Meno.

Husserl, E., 1976 (1913), Ideen zu einer reinen Phänomenologie und phänomenologischen Philosophie. Erstes Buch, Martinus Nijhoff, La Haya (Husserliana III/1). [Versión en castellano: Ideas relativas a una fenomenología pura y una filosofía fenomenológica, 2a. ed., trad. José Gaos, Fondo de Cultura Económica, Madrid, 1985.]

_ 1984 (1900), Logische Untersuchungen. Zweiter Band: Untersuchungen zur Phänomenologie und Theorie der Erkenntnis, Martinus Nijhoff, La Haya (Husserliana XIX/1 y XIX/2). [Versión en castellano: Investigaciones lógicas, 2: Investigaciones para la fenomenología y teoría del conocimiento, 2a. ed., trad. José Gaos y Manuel García Morente, Madrid, Alianza Universidad, 1985.]

—_, 1975 (1900), Logische Untersuchungen. Erster Band: Prolegomena zur reinen Logik, Martinus Nijhoff, La Haya (Husserliana XVIII). [Versión en castellano: Investigaciones lógicas, 1: Prolegómenos a la lógica pura, 2a. ed., trad. José Gaos y Manuel García Morente, Alianza Universidad, Madrid, 1985.]

Imdahl, G., 1997, Das Leben verstehen. Heideggers formal anzeigende Hermeneutik in den frühen Freiburger Vorlesungen (1919 bis 1923), Königshausen und Neumann, Wurzburgo.

Jaspers, K., 1967 (1919), Psicología de las concepciones del mundo, trad. Mariano Marín, Gredos, Madrid. 
Kalariparambil, T., 1999, Das befindliche Verstehen und die Seinsfrage, Duncker und Humblot, Berlín.

Kierkegaard, S., 1962 (1846), Abschließende unwissenschaftliche Nachschrift, en Gesammelte Werke, vol. VII, Eugen Diederichs Verlag, Colonia y Düsseldorf.

—_, 1955 (1850), Einübung im Christentum, en Gesammelte Werke, vol. XXVI, Eugen Diederichs Verlag, Colonia y Düsseldorf. [Versión en castellano: Ejercitación del cristianismo, trad. Demetrio Gutiérrez Rivero, Guadarrama, Madrid, 1961.]

Kisiel, T., 1996, "Ĺndication formelle de la facticité: sa genèse et son transformation", en Courtine 1996, pp. 205-210.

_ 1993 , The Genesis of Heidegger's Being and Time, University of California Press, Berkeley/Los Ángeles.

Marion, J.-L., 1989, Réduction et donation. Recherches sur Husserl, Heidegger et la phénoménologie, Presses Universitaires de France, París.

Oudemans, C.W., 1990, "Heideggers 'logische Untersuchungen'”, Heidegger Studien, vol. 6, pp. 85-106.

Pöggeler, O., 1991, "Heideggers logische Untersuchungen", en Forum für Philosophie Bad Homburg (comp.), Martin Heidegger: Innen- und Außensichten, 2a. ed., Suhrkamp, Fráncfort del Meno, pp. 75-100.

Rodríguez, R., 1997, La transformación hermenéutica de la fenomenología. Una interpretación de la obra temprana de Heidegger, Tecnos, Madrid.

Segura, C., 1999, "Heidegger 1922. Indicación de la situación hermenéutica", Revista de Filosofía, vol. XII, no. 21, pp. 77-113.

Streeter, R., 1997, "Heidegger's Formal Indication: A Question of Method in Being and Time", Man and World, vol. 30, pp. 413-430.

Volpi, F. (comp.), 1988, Heidegger et l'idée de la phénoménologie, Kluwer Academic Press, Dordrecht, Boston y Londres.

Watanabe, J., 1993, "Categorial Intuition and the Understanding of Being in Husserl and Heidegger", en J. Sallis (comp.), Reading Heidegger. Commemorations, Indiana University Press, Bloomington e Indianápolis, pp. 109-117.

Recibido el 12 de diciembre de 2002; aceptado el 1 de julio de 2003. 